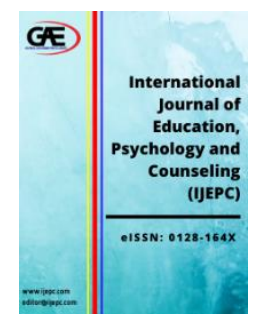

\title{
EFFECTIVENESS OF THE PEACE EDUCATION PROGRAM ON THE SOCIAL AND EMOTIONAL BEHAVIOUR FOR PRE- SCHOOL IN THE SULTANATE OF OMAN
}

\author{
Mahfouda Rashid Al Mushaqiri ${ }^{1 *}$, Zahari Ishak ${ }^{2}$, Wail Muin Ismail ${ }^{3}$ \\ 1 Department of Psychology, University of Malaya,, Malaysia \\ Email: mahfoodha1974@hotmail.com \\ 2 Department of Psychology, University of Malaya,, Malaysia \\ Email: irahaz@um.edu.my \\ 3 Department of Psychology, University of Malaya,, Malaysia \\ Email: wailismail@um.edu.my \\ * Corresponding Author
}

\section{Article Info:}

\section{Article history:}

Received date: 11.08 .2020

Revised date: 10.09 .2020

Accepted date: 12.09 .2020

Published date: 15.09.2020

\section{To cite this document:}

Al Mushaqiri, M. R., Ishak, Z., \& Ismail, W. M. (2020). Effectiveness of The Peace Education Program on The Social and Emotional Behaviour for Pre-School in The Sultanate of Oman. International Journal of Education, Psychology and Counseling, 5 (36), 211-225.

DOI: $10.35631 / \mathrm{IJEPC} .5360016$

\begin{abstract}
:
The present study aims at providing a peace education program for pre-school children through classroom teaching methods and processes. As peace education is an essential component of good basic education, it is an integral part of UNICEF's vision of basic education awareness. The Universal Declaration on Education for All (1990) (The Jomtien Declaration) clearly states that basic learning needs are not only essential tools such as literacy and numeracy but also knowledge, skills, attitudes, and values required to live, work with dignity and participate in development. It also states the InterAgency Commission, World Conference on Education For All (WCEFA., 1990) that meeting those needs entails responsibility and the promotion of social justice, acceptance of differences, and peace. Furthermore, the present study provided a peace education program (PEP) for pre-school children aged (4 - 6) years in Oman. Where the program contains (28) training sessions are offered within (15) weeks at the rate of one hour per session. The researcher used a scale of two images, the behaviour of the children was measured before and after the experiment, where the researcher adopted the quasi-experimental method, the sample consisted of (40) children in the experimental group and (40) children in the control group. In addition, the results of the current study were in favour of the experimental group, where an improvement in their behaviour was observed after being enrolled in the program. The study finds that pre-school education is very important to spread peace since it focuses on
\end{abstract}




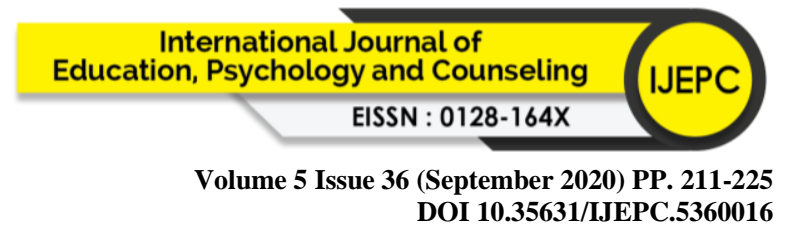

a critical era in children's life. Thus, the study recommends the ministry of education to consider the findings for a better peaceful learning environment.

Keywords:

Peace Education, Emotional Behaviour, Social Behaviour, Pre-School

\section{Introduction}

Peace is the highest level that who help spreads tranquillity, happiness, harmony and balance; not only with others. but is peace of mind and inner tranquillity with oneself of mind which is full of love and enables the ability to live tranquillity. Psychological peace and self-alignment is the top of the spiritual pyramid to live happily, with comfort and peace of mind. All of these could be gained through continuous training on how to deal with others on a win-win basis (AlSharqawi, 2014). In addition, the frequent listening to the human inner self makes one feel more calm and tranquil, so reverence in prayer and listening to the Quran, reading and its rhythm within the psychological conscience is a spiritual stop makes the psychological system of the Muslim at least five times a day and the greatest force and impact is the Fajr prayer (UNICEF., 2007), the evidence is the words of ALLAH: The Qur'an of dawn. Indeed, the recitation of dawn is ever witnessed. Peace is a human need, without which people live in terror and fear, lose their constancy and make them deal with the surroundings as enemies, lose friendship and respect for people. Peace education in UNICEF refers to the process of promoting knowledge, skills, attitudes and values needed to bring behavioural changes that support children, youth and adults and prevent conflict and structural violence. Furthermore, peace education helps children to peacefully resolve conflict; and create the conditions conducive to peace at personal, social and national levels (Nations., 2015). For example, when two or more people do something as a group, conflicts are likely to arise between them, due to individual differences. The peaceful coexistence of group members depends on their ability to manage conflict. In addition, peace education is a philosophy and process concerned with gaining knowledge about various aspects of peace, violence and peace-making skills. It is also the process of instilling elements of peace education in learners to enable them to develop their abilities to demonstrate tolerance and skills for solving non-violent conflicts and a sense of dedication in creating peace education (Akudolu, 2010). Harris and Morrison (2003), also noted that peace education not only guarantees a philosophical dimension such as love, mercy, respect and nonviolence, but is also a process that includes listening, meditation, thinking, cooperation and conflict resolution skills. As, we all today face many problems that threaten the whole world. One of the most serious of these problems is the problem of conflict and violence in its various forms, such as violence with self and social violence. It was therefore normal that the world represented in United Nations promotes a culture of peace in the world, especially among children (Al-Saeed, 2010).

Preschool education is one of the most important stages in child's mental, social, emotional, and linguistic development, consists of they constitute psychological construction on which the fundamentals of congenital mental health are based and at this stage changes occur in all types of growth, mental, physical, emotional, linguistic, social, and the maturity of each of them; the child's susceptibility to them is also affected by the factors surrounding it on a daily basis (Qenaoui \& Abdel Muti, 2000). 


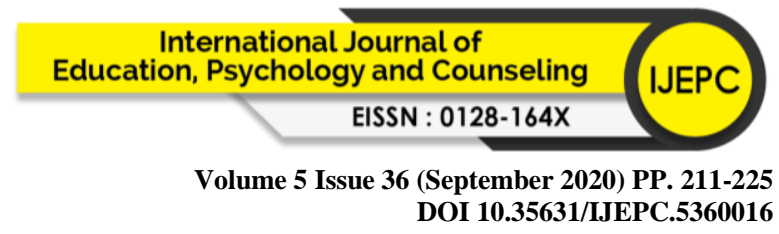

This confirms that the first years of a child's life are essential in composition of their intelligence, personality and social behaviour. Children are born with a range of social capacities, physical and psychological abilities enabling them to communicate, learn and develop; if they do not receive attention they seek from adults, such abilities may decrease. Studies also suggest that behaviour develops in children occurs before the age of seven, and because children are the future of our lives in next generations to come, they honour the values of culture and maintain the social and moral values. Therefore, it is very important to start by promoting these values with children through related useful educational programs (Salama, 2002). Oman Vision 20/40 stated that Oman seeks to be among the top ten countries that enjoy world peace (Council., 2019). The present study also came to support Oman's vision 20/40 for reaching the forefront of peace. The Omani society went through the eighties and nineties of the last century (beginning of the Renaissance in Oman) with a marked interest in children and their rights in an institutional way. Despite Oman's great interest in children, this interest focused more directly on their literacy and numeracy than on instilling the values of peace in children, which in turn had a negative impact on the behaviour of children, in which they played the roles of cartoon characters broadcast by modern media to them, since the children's stay in front of the television have become a major part of their time. Now is different from the past, due to many external influences affecting children, in addition, today's family is busy working outside the home dramatically, making children spending their time in front of television.

Despite all these external stimuli, the curriculum offered to pre-school children is still the same as in the past, which lack the implementation of the Convention on the Rights of the Child and the Children's Code. As, the evaluation of the Omani curriculum for preschool education carried out in 2010 by UNICEF with the Ministry of Education showed that there is weakness in the spiritual aspect, and we know that if the spiritual side of is strong, the child will gain good values from the earliest age. What is instilled in a person since childhood cannot be changed, this is the main principle that man lives throughout his life (Ministry of Education. \& UNICEF., 2010).

On the other hand, Muscat Daily (2018) showed there are 387 cases of abuses against children in Oman, which occurred between January and June 2018. As, there is a hotline in the Ministry of Social Development to report any cases of abuse (Al-Hajri, 2018). Despite the existence of the Omani Children's Code issued (Development., 2014), however, this is not enough; because children need to learn how to take preventive measures before the incident in order to protect themselves from any abuse that may occur. This in turn confirms to the researcher the firm desire to teach children to raise peace.

The researcher also believes that we need to develop a program for pre-school children which will help in teaching them some peace skills: love, tolerance, honesty, cooperation, respect, happiness, dialogue and protection, by this, children will be able to grow as peace-loving and peace-making. This is an attempt to engage in instilling peace in children from childhood to create a better world free from conflict and war. Peace is a human need, without which people live in terror and fear, lose their constancy and make them deal with the surroundings as enemies, lose friendship and respect for people, while people cannot live in isolation.

Peace has as many definitions as its types and thus it might not be easy to have one unified definition i.e. Johnson (2005) argued that peace concept is problematic for it has multiple 


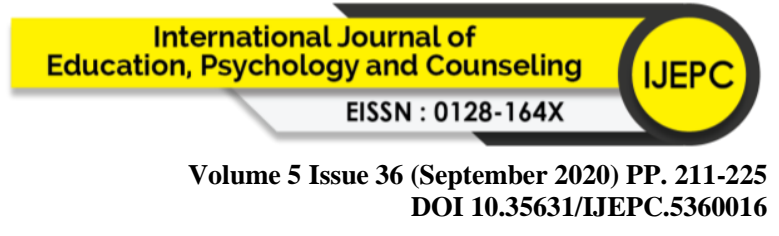

meanings and perspective related to different standards and criteria. Such lack of agreement and consensus determine of whether peace exists as something or as an abstract notion referring to the absence of war and violence. Johnson and Johnson's definition of peace, for instance, have been significantly supported that "peace is not the absence of war, just as health is more than the absence of disease" (pp. 276-277).

The current study sought to modify children's social and emotional behaviour through the peace education program. Social behaviour is a set of works, performances, experiences, and activities that pre-school children learn and repeat, and they train in a regular manner until they enter into their social interaction with others and the things around them (Hassouna, 2007). Emotional behaviour is defined as the way in which children acquire knowledge, skills and attitudes to know their feelings and how to manage them, set positive goals to achieve them, care for others, establish and maintain positive relationships with them, make responsible decisions and deal with personal situations effectively (Payton et al., 2008).

\section{Review Objectives and Hypotheses}

The current study aimed to build a Peace Education Program (PEP) that demonstrates social and emotional behaviour in children. Accordingly, the objectives of the study came as follows:

In order to determine whether there are statistically significant differences in the social behaviour of pre-schoolers between the experimental group and the control group after the Peace Education Program (PEP), the first hypothesis came: There are no statistically significant differences in the social behaviour of children at some point Pre-school between the experimental and control group after PEP;

In order to determine whether there are statistically significant differences in the emotional behaviour of pre-schoolers between the experimental group and the control group after PEP, the second hypothesis came which is: There are no statistically significant differences in the emotional behaviour of pre-schoolers between the experimental group and the group Control subjects after PEP;

As for determining whether there are statistically significant differences between males and females in pre-school stage in social and emotional behaviour after infection with PEP, the third hypothesis came: There are no statistically significant differences between males and females in pre-school stage in Social and emotional behaviour after PEP.

To answer the research questions and investigate the accuracy of the proposed hypotheses, the study has integrated two theories from which the researcher has formulated a new framework to analyse the data as follows: Maslow's theory argues that human beings have basic needs to be fulfilled first and on which other needs are based. That is children's basic needs ought to be fulfilled and then other needs with higher virtues such as co-existence and peaceful life and constructive dialogues are fulfilled. The study adopted Maslow's theory because of its emphasis on individuals' constructive dialogue, respect, love, peace, cooperation, tolerance and honesty with one another. In other words, pre-schoolers can reach to and possess such virtues after they reach to self-realization comprehensively built on other needs on the hierarchy including the most significant one at the base of the pyramid. Along with Maslow's theory, this study is built on Daniel Goleman's Model (1995). As mentioned earlier, Goleman's 


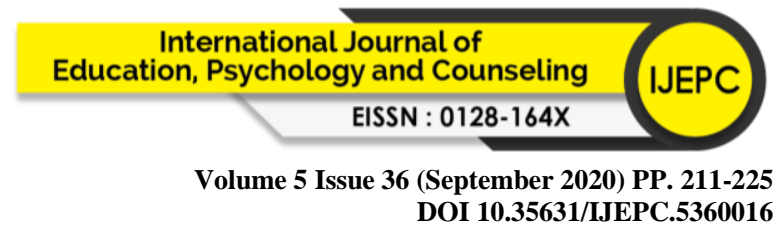

theory sheds light on emotional intelligence which generates/is associated with a range of different behaviours, the most important of which as claimed by Goleman (1995) is emotional behaviour, based on which many human characteristics and virtues can be analyzed/measured. Since this study investigates the dimensions of the traits and faults of emotional behaviour, the proposed theory is the most applicable one to provide a new explanation for the causes of the problems of emotional behaviour that negatively influence the process/environment of peace education of pre-school students. The results of the possible problems of emotional behaviour generated by this theory may greatly help decision-makers and other personnel to take the necessary steps and procedures in making/finding proper solutions that help promote and spread peace education at pre-schools in Sultanate of Oman.

\section{Literature Review}

Al-Saidi (2013) evaluated the effectiveness of enrichment activities in planting the concepts of peace in kindergarten children. To achieve the objectives of the study, the semi-experimental method was used on a random sample $(n=46)$ of kindergarten children in the Holy City in the second semester of 2013. The sample included 23 children of the experimental group, and 23 children in the control. The researcher prepared a daily program concerning the education of peace (Peace Unit). The researcher concluded that integrating peace education in the curricula enriches the kindergarten programs, which thus boost students' motivation and desire to effectively and quickly learn. A significant study was conducted by Darweish and Abdulsamad (2017) about peace education existence and influence in education in schools in Iraqi Kurdistan. The authors adopted qualitative research approach and critical discourse analysis to shed light on the content of educational textbooks in respect with violence, principles and values. The author concluded that Kurdistan's school curriculum suffers from different issues including violence, inequality and discrimination, which are caused by the dominant political group. Such issues have serious academic and socio-psychological impact on school children. The authors emphasised that Kurdistan's curriculum lacks the core foundations necessary to enhance students' cultural and ethnic backgrounds. The study finally found that the terminologies, concepts and words used in school textbooks focus on Muslims' alienation of the other ethnic groups rather than on the more positive aspects of Islam that should be learned and shared. Thus, it is hardly to find essential terms such as peace, equality and tolerance used in the curriculum due to the dominant group promulgating its knowledge as a sign of domination and influence. Very recently, Murano, Lipnevich, Walton, Burrus, Way \& Carrasco (2020) conducted a study about measuring social and emotional skills in elementary students. They conducted two searches to develop and validate items in order to measure emotional and social skills in third, fourth and fifth grade students. Having applied Big Five personality model as an assessment framework, the authors concluded that emotional and social skills can be validly and reliably measured in elementary students. The authors also concluded that teamwork is the most important factors leading elementary students for academic success and achievement.

In astonishing paper written by Panayiotou \& Wigelsworth (2019), social and emotional behaviours were exclusively investigated. The authors investigated a longitudinal sample of 1626 students attending 45 elementary schools in the UK. Having used structural equation modelling accounting for data-clustering, prior academic attainment, gender and within-time covariance, the authors examined the temporal relations between school connectedness, mental health difficulties, social-emotional competence and academic attainment. The authors 


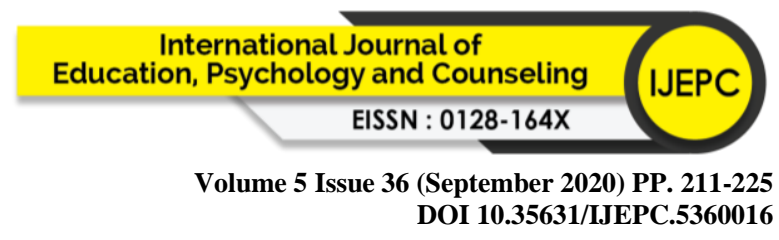

emphasized that social- emotional competence exerted a valuable influence on school students' mental health difficulties and school connectedness. The authors concluded that students who have greater social-emotional competence experience fewer mental health issues and difficulties and thus they may have higher academic attainment.

Al Sawafi (2015) conducted a study to measure the effectiveness of a training program in developing some social skills among a sample of pre-school children. Three social skills were identified (empathy, communication with others, cooperation). The program was applied to a sample of (20) pre-school children (ranging from 4-6) years from Sanao Private School in Sharqiyah North Governorate in the Sultanate of Oman. The researcher used the Social Intelligence Scale in the study of Al-Qatami and Al-Yousef (2010), which consists of a photographic scale and a note form for the teacher. The results of the study confirmed the correctness of the first hypothesis about the presence of statistically significant differences in the social skills (empathy, communicate with others, cooperation) with pre-school children in the first and second measurements. This is because of the training program used in this study. The results also confirmed the second hypothesis which indicates that there are no statistically significant differences between the second and follow-up measurements in social skills (empathy, communicate with others, cooperation) among a sample of pre-school children.

Olowo (2016) investigated the effects of integrating Peace Education in Nigeria educational system. Four research questions were designed. The researcher designed an instrument tagged concerning questionnaire on effect of Integrating Peace Education (QEIPE). The entire population of the two hundred respondents spread across secondary schools. This took place at higher institutions of learning in Ondo State. A 20-item questionnaire structured on a 4-point scale was used for the collection of data. Mean and Standard deviation was used to answer the fourth research question generated from the study. The study stressed the significance of integrating peace education in the curriculum of Nigerian schools in order to reduce crime, violence and other social vices in Nigeria. The result of the study further revealed that there are no significant differences between Peace Education and Social Studies. The findings identified the relevant effects of integrating Peace Education in the school curriculum on teachers and students. of the study emphasized the significance of training teachers to promote peace education between learners.

Al Maimouni (2018) discussed the effectiveness of a kinetic activity program in developing emotional stability in kindergarten children. The researcher used a quasi-experimental approach based on dividing the groups into two groups: experimental group and control group. The research consisted of two types of samples: exploratory including 27 boys and 30 girls between 5 to 6 years in Al-Narjis Kindergarten in Al-Ahmadi Educational Area in Kuwait. The standard deviation was (1.9) years in order to calculate the psychometric characteristics of research tools. The main research sample consisted of 40 boys and girls in Al-Istiklal Kindergarten of Al-Ahmady Educational Zone between 5 to 6 years. They were divided into two groups: males with an average age of (5.3) years, a standard deviation of (1.4) years, and a control group consisting of 20 boys and girls (10 females, 10 males). The researcher used Stability Scale for Kindergarten Child and the program of motor activities to develop emotional stability. The study found that there are statistically significant differences between the mean scores of the pre and post measurements of the children of the experimental group in the emotional stability after the application of the program in favour of the post application. There 


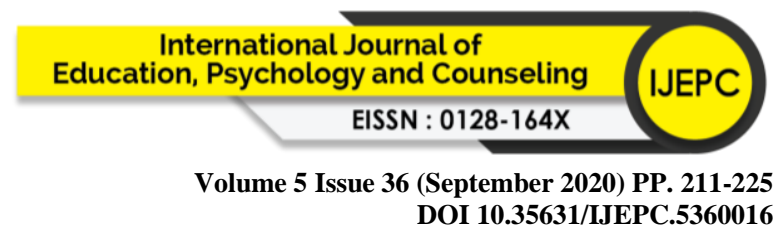

are statistically significant differences between the mean scores of the experimental group children and the control group children in the dimension of emotional stability after applying the program for the experimental group.

\section{Methodology}

The present study was based on the quasi experimental approach; its purpose is to evaluate the effect of the Peace Education Program (as an independent variable) on emotional behaviour (as a dependent variable) for pre-school children in Oman.

The researcher used a quasi - experimental design approach of two unequal groups: control group, and experimental group, and children from KG2 class were selected from two different classes, the sample of the study $(\mathrm{N}=80)$ was homogeneity in the gender and number of children between the experimental and control groups. The study included 42 males and 38 females with 40 children in the experimental group and 40 in the control group.; then both groups undergo a pre-test. After that the experimental group was then subject to the independent variable and the control group is not. Finally, at the end of the experiment, the experimental and control groups are given the post-test to evaluate the effect of the independent variable application.

\section{Data Analysis And Findings}

Normality tests were performed to ensure sample normality, subsequently, ANCOVA test was performed as an inferential analysis, in order to examine the study hypothesis.

\section{Table 1: Normality Tests For Study Variables}

\begin{tabular}{|c|c|c|c|c|c|}
\hline & Variable & Mean & SD & Skewness & Kurtosis \\
\hline \multirow{3}{*}{ 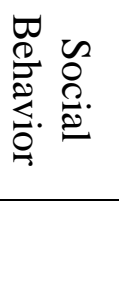 } & Self-Care Skills & 1.4938 & .26821 & .731 & -.475 \\
\hline & Communication Skills & 1.5896 & .23562 & .673 & -.609 \\
\hline & Variable & Mean & SD & Skewness & Kurtosis \\
\hline \multirow{2}{*}{ 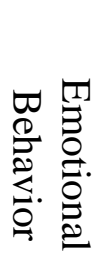 } & Self-Awareness & 1.7650 & .20256 & -.524 & -.339 \\
\hline & Empathy & 1.7458 & .18966 & -.340 & -.688 \\
\hline
\end{tabular}

$\mathrm{SD}=\overline{\text { Standard }}$ Deviation

Table (1) shows the values of skewness and kurtosis as the normality tests and the mean and the standard deviation for each variable for the study variables. The results show that all variables are considered normally distributed as the skewness and kurtosis values are between \pm 2 which is considered acceptable according to George \& Mallery (2016). 
Figures 1,2,3,4 Shows the Normality Curves Which Indicate Clearly the Bell Shape.

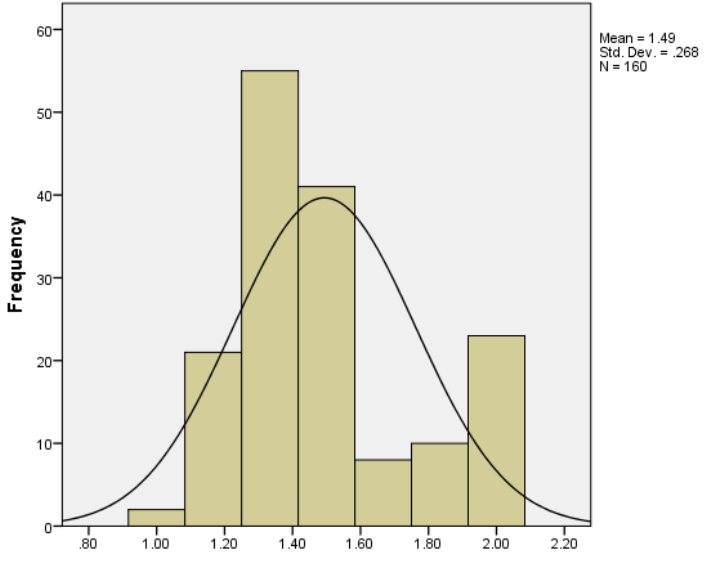

Figure 1: Self-Care Skills

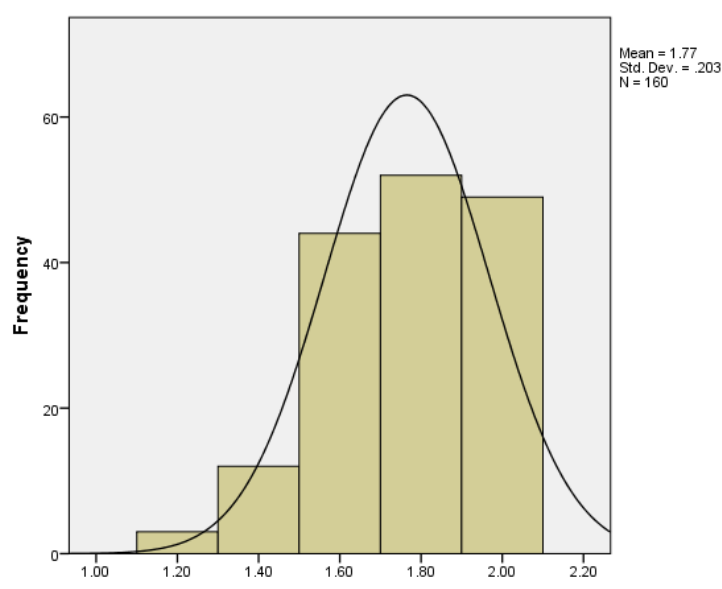

Figure 3: Self Awareness

Testing Research Hypotheses

The research hypotheses are tested:

1. Testing the differences in the social skills of preschool children between the experimental and the control group of the (PEP). The first hypotheses assumes that there are no significant differences in the social skills of preschool children between the experimental and the control group of the peace education program (PEP) which means that there is a pre-test and a post-test for each social skills also there is an independent variable with two groups (control and experimental), so by using ANCOVA test, the independent variable will be the students' group (control and experimental), the dependent variable will be the post-test and the covariate variable is the pre-test. The ANCOVA test results are shown in table (2). 
Table 2: ANCOVA Results For Testing The Differences In The Social Skills Of Preschool Children Between The Experimental And The Control Group Of The (PEP)

\begin{tabular}{lcccccr} 
Variable & Test & Mean & S.D & F & Sig. & $\begin{array}{r}\text { Effect } \\
\text { Size \% }\end{array}$ \\
\cline { 1 - 4 } Social & Control & $\mathbf{1 . 4 3 1 9}$ & .06097 & & & \\
\cline { 2 - 5 } & Experimental & $\mathbf{1 . 9 3 0 6}$ & .05731 & & $\mathbf{. 0 0 0}$ & $\mathbf{9 5 . 4}$ \\
\hline
\end{tabular}

Sig. $<.05$

Table (2) shows that there are significant differences in social skills of preschool children between the experimental and the control group after receiving the peace education program (PEP) whereas the significance level is .000 which is less than .05 meaning that social skills of the preschool children significantly enhanced after receiving the PEP. This is indicated also by noticing the mean values before $(M=1.43)$ and after $(M=1.93)$ the PEP with an effect size percentage of .95

As a result, we can reject the null hypothesis and accept the alternative hypothesis as the social skills of the pre-schoolers have enhanced significantly after receiving the peace education program $(P E P)$.

2. Testing the differences in the emotional behaviours of preschool children between the experimental and the control group of the (PEP) The second hypothesis assumes that there are no significant differences in the emotional behaviours of preschool children between the experimental and the control group of the peace education program (PEP) which means that there is a pre-test and a post-test for emotional behaviours also there is an independent variable with two groups (control and experimental), so by using ANCOVA test, the independent variable will be the students' group (control and experimental), the dependent variable will be the post-test and the covariate variable is the pre-test.

The ANCOVA test results are shown in table (3).

Table 3: ANCOVA Results For Testing The Differences In The Emotional Behaviors Of Preschool Children Between The Experimental And The Control Group Of The (PEP)

\begin{tabular}{ccccccr}
\multirow{2}{*}{ Variable } & Test & Mean & S.D & F & Sig. & $\begin{array}{r}\text { Effect } \\
\text { Size \% }\end{array}$ \\
\cline { 1 - 5 } Emotional & Control & $\mathbf{1 . 6 8 1 3}$ & .10669 & & & \\
\cline { 2 - 5 } & Experimental & $\mathbf{1 . 9 5 0 0}$ & .04419 & & $\mathbf{. 0 0 0}$ & $\mathbf{7 9 . 5}$
\end{tabular}

Sig. $<.05$ 


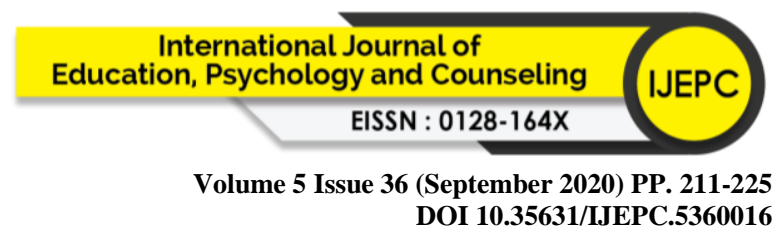

Table (3) shows that there are significant differences in emotional behaviors of preschool children between the experimental and the control group after receiving the peace education program (PEP) whereas the significance level is .000 which is less than .05 meaning that emotional skills of the preschool children significantly enhanced after receiving the PEP. This is indicated also by noticing the mean values before $(\mathrm{M}=1.68)$ and after $(\mathrm{M}=1.95)$ the PEP with an effect size percentage of .80

As a result, we can reject the null hypothesis and accept the alternative hypothesis as the emotional behaviors of the preschool children have enhanced significantly after receiving the peace education program (PEP).

3. Testing the differences between male and female preschool children in social and emotional behaviour after having the (PEP). In order to test the third hypothesis, Independent-sample t-test is used which the independent variable will be the students' gender (male and female) and the dependent variables will be the emotional and social behaviour dimensions and the results are shown in table (4).

Table 4: Independent-Sample T-Test Results

\begin{tabular}{|c|c|c|c|c|c|c|}
\hline Variable & Group & Mean & SD & $\mathbf{T}$ & df & Sig. \\
\hline \multirow{2}{*}{ Self-Care Skills } & Male & 1.8981 & .12959 & \multirow{2}{*}{-.081} & \multirow{2}{*}{38} & \multirow{2}{*}{.936} \\
\hline & Female & 1.9015 & .13273 & & & \\
\hline \multirow{2}{*}{ Communication Skills } & Male & 1.9537 & .07681 & \multirow{2}{*}{-.358} & \multirow{2}{*}{38} & \multirow{2}{*}{.722} \\
\hline & Female & 1.9621 & .07149 & & & \\
\hline \multirow{2}{*}{ Self-Awareness } & Male & 1.9111 & .12314 & \multirow{2}{*}{-.674} & \multirow{2}{*}{38} & \multirow{2}{*}{.505} \\
\hline & Female & 1.9364 & .11358 & & & \\
\hline \multirow{2}{*}{ Empathy } & Male & 1.9630 & .07130 & \multirow{2}{*}{.037} & \multirow{2}{*}{38} & \multirow{2}{*}{.97} \\
\hline & Female & 1.9621 & .07149 & & & \\
\hline
\end{tabular}

Sig. <.05

Table (4) shows that there are no significant differences in all social and emotional behaviors of preschool children between male and female students after receiving the peace education program (PEP) whereas the significance levels are more than 0.05 for all variables meaning that student gender does not affect the social and emotional behaviors of the preschool children after receiving the PEP.

As a result, we accept the null hypothesis as there are no statistically significant differences between male and female preschool children in term of social and emotional behaviour after receiving the peace education program (PEP). 


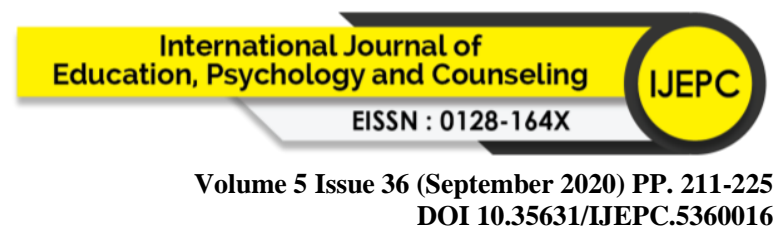

\section{Discussions And Conclusions}

The first hypothesis, there are no significant differences in the social behaviour of preschoolers between the experimental and the control group after the Peace Education Programme (PEP). The results of this hypothesis indicated that there are statistically significant differences between the experimental and the control in favor of the experimental group with effect size large, that are due to several factors:

First: Training received by children of the pilot sample during the implementation of the Peace Education Program, which included a range of activities, methods, and different methods appropriate for pre-school education, the program also included meaningful educational games related to program topics and practical activities implemented with children.

Second, the school administration responded positively to the program and the teacher excelled and cooperated with the researcher to implement the PEP with children. Finally, parents' cooperation, acceptance and encouragement of the program, as well as the enthusiasm of children to participate in the PEP. In addition, there is no one who lives alone in isolation from others completely, sleep and food habits are all behaviours that stem from social reality and aim to influence it (Hussain \& Bushra, 2013). Attention to social skills is also attributed to being an important determinant of the child's daily interactions. Children live in a network of relationships involving parents, peers, relatives and teacher (Al Said, 2005). Moreover, Al Sayed added that social skills are the key to building the child's personality and acceptance as an active member of society in the future, and these skills are laid in early childhood. The results of the present study are consistent with the findings with studies by (Al-Saidi, 2013., \& Al Maimouni, 2018), which revealed the existence of statistically significant differences between the experimental and control group in the post-test and for the benefit of the experimental group trained in the program.

Based on the above, social skills are essential for the individual from a young age. However, despite the interest of researchers in the field of social skills, they still did not receive sufficient attention. Therefore, the current study is designed to train children to enhance some social skills in them, such as (self-care skills, communication skills). Thus, the results of the study demonstrated its rejection of the hypothesis that there were no differences in social behaviour between the children of the experimental group and the control group after the Peace Education Program (PEP). The results of the current study showed that the behaviour of children in the experimental group has improved significantly after the PEP in communication skills are a little more than interpersonal relation skills and self-care skills. Also, Interpersonal relation skills had a greater impact than self-care and led to a better improvement in children's behaviour. Despite these differences in impact, all skills associated with social behaviour have significantly improved children's behaviour, therefore, the study emphasizes the importance of paying attention to the social behaviour of pre-school children and increasing research on this aspect (Qasem, 2011).

The second hypothesis, there are no significant differences in the emotional behaviour of preschoolers between the experimental and the control group after the Peace Education Programme (PEP). The results of this hypothesis show that there are statistically significant differences between the experimental and the control in the emotional behaviour attributed to the experimental group that were exposed to the PEP with effect size large. This is due to the Copyright $\odot$ G GOBAL ACADEMIC EXCELLENCE (M) SDN BHD - All rights reserved 


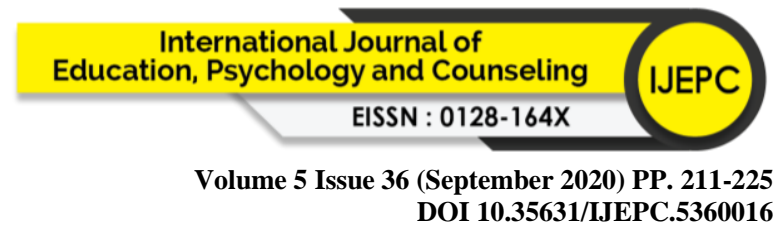

importance of training all pre-school children in Oman in the peace education program and its inclusion in the curricula offered to children of this category, as well as training pre-school teachers in its application to make it easier for them to deliver correctly. Where the social and emotional development of children aims to get rid of self-centred and the ability to control emotions and good behaviour with others, pre-school institutions contribute to the emotional growth of children by developing the ability to act without compromising others, as well as the ability to understand the feelings and needs of others. The emotional growth needs of the child lie in the need for a sense of security, which makes the child trust in himself and other and this feeling helps to start in them game and in thinking and relationship with adults, and the need for love and kindness, and the child's sense of being desirable and vice versa, while the child's feeling of being undesirable, leads to isolation and introversion from others and lack of selfconfidence. The significant difference between the experimental and control group members in emotional behaviour, based on the results of the post-estimation and for the benefit of the experimental group, this is due to the fact that the members of the control group did not recognize the mistakes they made while answering tribal appreciation and did not practice the peace education program, leaving them at the same level and without showing any development or improvement in their social and emotional behaviour. The current study concurred with studies such as (2002; Al Riasite, 2010), they agreed on the importance of training children on emotional behaviour and promoting values in themselves to live in stability and be active in society. The current study in the research sample differed with a study by (Nilufer, 2006) that were applied with the family. Based on the above, emotional skills are essential for the individual from a young age. However, despite the interest of researchers in the field of emotional skills, they still did not receive sufficient attention. Therefore, the current study is designed to train children to enhance some emotional skills in them, such as (selfawareness skills, empathy skills). Thus, the results of the study demonstrated its rejection of the hypothesis that there were no differences in emotional behaviour between the children of the experimental group and the control group after the Peace Education Program (PEP). The results of the present study showed that the emotional behaviour of children in the experimental group improved significantly after PEP in the following order (empathy - self-awareness). Despite these differences in impact, all skills associated with emotional behaviour have improved the behaviour of pre-school children who have received training in the program. Therefore, the study emphasizes the importance of caring for the emotional behaviour of preschool children and increasing research in this aspect.

The third hypothesis, there no significant differences between male and female pre-schoolers in social and emotional behaviour after having the Peace Education Programme (PEP).

The results of the third hypothesis indicated that are no statistically significant differences between male and female preschool children in term of social and emotional behaviour after receiving the peace education program (PEP). The explanation for this result is due to the importance of training all pre-school children (male and female) in Oman in the peace education program and its inclusion in the curricula offered to children of this category, as well as training pre-school teachers in its application to make it easier for them to deliver correctly.

The results explain that everyone needs peace education, and there is no difference between males and females in the level of vulnerability to peace training. The current study concurred with studies such as (Al Said, 2005; Al Maimouni, 2018). The current study in the research 


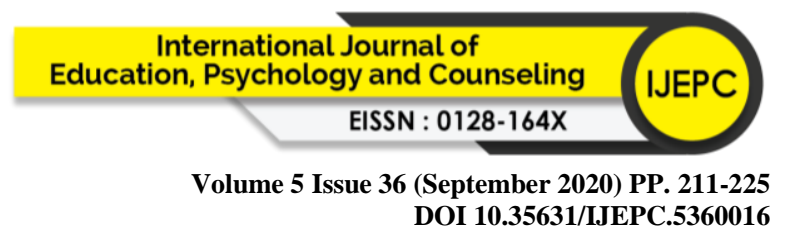

sample differed with a study by (Al Hajj, 2013) that were statistically significant differences in the school social behavior depending on gender for the sample of the male; and statistically significant differences in self-concept depending on the gender for the sample of the male. Also, differed with study by Abd Al Jalil (2018) in the presence of statistically significant differences between males and females after enrolling in the program, and for the benefit of females.

\section{Conclusions}

The impact of the peace education program on the social and emotional behaviour of preschool children. Peace is an important prerequisite for the development of a balanced life for people, especially when it begins to behave from childhood.

The study aims at instilling the values of peace education in the behaviour of children in the Sultanate of Oman. Moreover, it aims to determine the impact of the Peace Education Program on the social and emotional behaviour of preschool children.

The results may provide the benefit of measuring and improving children's behaviour through program objectives and activities and may support the curriculum in Oman. Moreover, this study attempted to focus on some aspects of growth and behaviour enhancement. It is likely to be beneficial to learners, teachers, curriculum designers, and educational policymakers in Oman.

\section{References}

Akudolu, L. (2010). The format, non- format and informat continuum in peace education curriculum. $8^{\text {th }}$ biennial conference on development peace education curriculum for Nigeria, 18-23 October 2010.

Abd Al Jalil, N. (2018). The effectiveness of using e-learning in giving kindergarten children some concepts of peace education. Unpublished Master Thesis. South valley university . Egypt.

Akudolu, L. (2010). The format, non- format and informat continuum in peace education curriculum. $8^{\text {th }}$ biennial conference on development peace education curriculum for Nigeria, 18-23 October 2010.

Al Rayasti, R. (2010). Emotional intelligence and its relation to psychological and social compatibility in a sample of children (13-16) years. Childhood studies, 6(13), 123- 154.

Al Maimouni, S. (2008). The effectiveness of a program of dynamic activities in the development of emotional stability of the kindergarten child of Kuwait. Benha University, Faculty of Specific Education, Department of Kindergarten. Egypt.

Al-Hajri, S. (2018). Sharp rise in child abuse cases in Jan-June 2018. Muscat Daily. On October 03, 2018. Oman.

Al-Saeed, N. (2010). An analytical study of the components of the culture of peace in children's stories published by the State Information Service and presented to the Egyptian child. (PhD), Ain Shams University, Egypt.

Al-Saidi, R. (2013). The effectiveness of enrichment activities in giving kindergarten children the concepts of peace. (PhD), Umm Al-Qura University, Saudi Arabia.

Al Said, R. (2005). Effectiveness of a program of psychosocial activities in the development of some social skills of preschool children. Egypt: Zagazig University. 


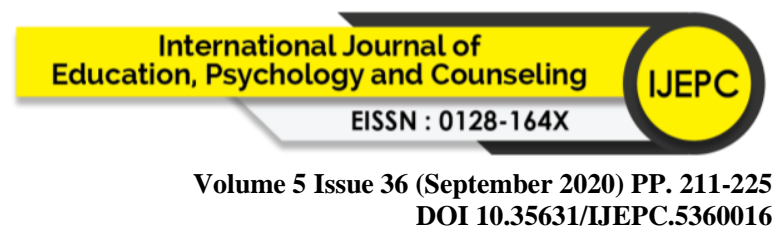

Al Sawafi, G. (2015). The effectiveness of a training program in developing some social skills among a sample of preschool children, Master thesis. Department of Education and Humanities. University of Nizwa. Oman.

Al-Sharqawi, M. (2014). Peace begins from kindergarten. Retrieved from http://www.ahram.org.eg/NewsQ/279923.aspx

Darweish, M., \& Abdulsamad, M. (2017). History education in schools in Iraqi. Kurdistan: representing values of peace and violence, Journal of Peace Education, DOI: 10.1080/17400201.2017.1409198.

George, D., \& Mallery, P. (2016). IBM SPSS statistics 23 step by step: A simple guide and reference. Routledge.

Gleitman, H., Fridlund, A., \& Reisberg, D. (2004). Psychology. $6^{\text {th }}$ ed. New York: Norton \& Company.

Harris, I. M. (2003). Peace education at the end of a bloody century. Educational Studies, 34(3), 336-351.

Hassouna, A. (2007). Social skills of kindergarten child. Egypt: International House for publishing and Distribution.

Hussain, J., \& Hussain \& Bushra, K . (2013). Social behavior and its relationship to the concept of self among students of the Faculty of Fine Arts at the University of Babylon. Journal of the Babylon Center for Humanities, 4(2), 43-102.

Johnson, D., \& Johnson, R. (2005). Teaching students to be peacemakers: A Meta-Analysis. Paper presented at the Annual Meeting of the American Educational Research Association. Seattle, WA, April 10-14, 2001.

Maslow, A. (1968). Towards a psychology of being (2 ${ }^{\text {nd }}$ ed). New York: Van Nostrand.

Ministry of Education., \& UNICEF. (2010). Evaluation of the Omani curriculum for preschool education. Ministry of Education, Oman.

Ministry of Social Development. (2014). Omani Child Law. Issued by Royal Decree No. 22/2014. Sultanate of Oman.

Muranoa, L, Walton, B, Way \& Carrasco. (2020). Measuring social and emotional skills in elementary students: Development of self-report Likert, situational judgment test, and forced choice items. Journal of Personality and Individual Differences. Articles is in press.

Nations., U. (2015). Preventing conflict, transforming justice and ensuring peace. A global study on the implementation of United Nations Security Council Resolution 1325. United State.

Nilufer, O. (2006). Emotional intelligence and family environment. The Journal of Social Issue, $16,169-175$.

Olowo Olusegun, O. (2016). Effects of Integrating Peace Education in the Nigeria Education System. Journal of Education and Practice. www.iiste.org ISSN 2222-1735 (Paper) ISSN 2222-288X (Online) Vol.7, No.18, 2016.

Payton, J., Weissberg, R. P., Durlak, J. A., Dymnicki, A. B., Taylor, R. D., Schellinger, K. B., \& Pachan, M. (2008). The positive impact of social and emotional learning for kindergarten to eighth-grade students: Findings from three scientific reviews. Chicago, IL: Collaborative for Academic, Social, and Emotional Learning.

Panayiotou, H., \& Wigelsworth (2019). An empirical basis for linking social and emotional learning to academic performance. Contemporary Educational Psychology January 2019. Volume 56. 193-204 
Volume 5 Issue 36 (September 2020) PP. 211-225 DOI 10.35631/IJEPC.5360016

Qasem, A. (2011). Abraham Maslow, s theory of human motivation. Foundations of Education. Education and Culture. Retrieved from http://al3loom.com/?p=1357.

Qenaoui, H., \& Abdel Muti, H. (2000). Growth psychology. House of Quba. Cairo.

Racdhi, F. (2002). The impact of parental abuse and neglect on the cognitive, emotional and social intelligence of children. Egyptian Journal of psychological studies, 12(36), 4685.

Salama, F. (2002). Environmental Education for Kindergarten Child. Reference Series in Education and Psychology. Arab Thought House. Cairo.

Supreme Planning Council. (2019). Oman Vision 20/40. Muscat. Oman.

UNICEF. (2007). Report on the Culture of Peace in the World. Peace Culture Foundation (M. Yousef, Trans.). Library of Alexandria, Egypt. 